\title{
A survey of the practice of a large-scale implementation of inquiry-based mathematics teaching: from Taiwan's perspective
}

\author{
Erh-Tsung Chin · Fou-Lai Lin
}

Accepted: 30 September 2013/Published online: 17 October 2013

(c) FIZ Karlsruhe 2013

This is a brief commentary from the perspective of Taiwan. We first introduce the background of Taiwan's involvement in the global educational reform related to inquiry-based learning in mathematics and science. In the main part, we share some important ideas based on our experiences of conducting nationwide teacher professional development projects in Taiwan, followed by some discussion and suggestions. The commentary concludes with some remarks.

Inquiry-based learning (IBL) has been a popular issue in the trend of science and mathematics education reform for decades all over the world. More than 20 years ago, the National Council of Teachers of Mathematics (NCTM) indicated that inquiry is one of the most important contexts for students' learning of mathematical concepts and knowledge, to include exploring, conjecturing, reasoning logically and evaluating whether something makes sense or not (NCTM 1991). As an active member of the global village, Taiwan, of course, is part of this global trend of educational reform. Even though our student performances in international assessments, such as TIMSS and PISA, are always among the leading group of the world (Mullis et al. 2008, 2012; Organization for Economic and Co-operation Development (OECD), 2005), students' low learning motivation and lack of inquiry habits of mind have been noted by both researchers and the government (Lin and Liu 2011). As a result, many research projects about science and mathematics inquiry have been conducted by

\section{E.-T. Chin $(\bowtie)$}

Graduate Institute of Science Education, National Changhua

University of Education, Changhua, Taiwan

e-mail: abegracechin@hotmail.com

F.-L. Lin

Department of Mathematics, National Taiwan Normal

University, Taipei, Taiwan researchers within the last 20 years. The National Science Council also implemented a nationwide "High Scope Project" (NSC 2006) 7 years ago for promoting senior and vocational high school students' science and mathematics inquiry competences. Further, many individuals, institutions and governmental organizations have supported professional developments for teachers in various aspects of IBL for more than a decade [e.g., teacher professional development for IBL teaching has been one of the themes of the calls for projects from NSC for 10 years; see http:// www.nsc.gov.tw/sci/lp.asp?CtNode $=1618 \&$ CtUnit $=1221 \&$ BaseDSD=7 (in Chinese)].

In this issue of $Z D M$, nine papers are included focusing on inquiry-based mathematics education (IBME) and its implementation. It is our pleasure to share some opinions based on the experiences of educational reform in Taiwan.

\section{Some ideas based on our experiences in Taiwan}

\subsection{Impediments to implementing day-to-day IBME}

Although most teachers possess a positive disposition towards IBL/IBME, their teaching practices are not consistent with it, being rather more expository oriented. This phenomenon is also the case in Europe, but occurs in Taiwan more conspicuously. The reasons behind this phenomenon are not fully understood. However, some impediments to carrying out day-to-day IBME might be generalized as follows (Chin 2008, 2011):

1. teachers did not experience IBL in mathematics when they were at school;

2. teachers do not have complete understanding of IBL/ IBME; 
3. the allocated teaching hours are not enough;

4. the great influence of "teaching to the test";

5. being alone and lack of administrative support from school or government.

As can be seen from the other papers of this issue, these impediments are also of importance in Europe.

\subsection{The transforming of mathematics teacher professional development in Taiwan}

More than 10 years ago, the Ministry of Education (MoE) in Taiwan started to advance the cultivation of "seed teachers" enthusiastically with the expectation that these "seeds" could blossom (influencing their peers) and bear fruit (materializing in the success of educational reform) in the near future. However, many years of endeavor did not result in satisfactory rewards. Most of the seed teachers did get good professional development themselves, but their influences seldom spread out to their peers. The main reason for this is that the "soil" around these "seeds" is too infertile for the seeds to blossom and bear fruit. Therefore, $\mathrm{MoE}$ began to adjust the strategy from recruiting individual teachers as seeds of reform to school-based professional development. The considerations behind this transform were basically to deal with the "soil" and trying to solve the aforementioned fifth impediment directly. A year ago, the nationwide "Light Spot for Mathematics Teaching" project (LSMT) (Lin 2013a) was carried out which required that the principal and all mathematics teachers of each participant primary or junior high school must sign a letter of consent to participate in twelve 3-h workshops led by a teacher educator (who is also a mathematics educator from a university) within an academic year (6 workshops in a semester). The aim of LSMT is to facilitate teachers' professional development by means of long-term continuing support. There are several topics, including IBL, ICT integrated teaching, mathematics proficiency, conjecturing and argumentation, models and modeling, and reading comprehension, for the 45 participant schools (26 primary and 19 junior high schools) to choose from. Taking the IBL group as an example, the design of the 12 workshops consists of experiencing IBL activities as a learner, literature reviews for constructing the theoretical backing for IBL, exemplary teacher's demonstration of IBL teaching, and designing and implementing their own IBL activities through action research. During the first year of running LSMT, professional development did start to flourish in most of the participant schools. However, we still noticed a lack of experience for most of the teacher educators in leading a teacher professional development community. Hence, another workshop called the "Lighting Up" project (Lin 2013b) has been organized to help the teacher educators become more competent at leading school-based teacher professional development communities.

"Light Spot for Mathematics Teaching" is a large-scale project initiated by the government. Whereas in PRIMAS (see Maaß and Doorman 2013) there are about 100 voluntary participant teachers in each consortium country, LSMT is school-based like IMST (Krainer and Zehetmeier 2013) and all the mathematics teachers of the 45 participant schools have to attend the project (about 600 mathematics teachers in total participated in LSMT in the first year). The focus of LSMT is provision of long-term support for teachers who form a school-based professional development community. However, the idea of running the adjunct "Lighting Up" project of LSMT seems consistent with the multipliers' education in the design of PRIMAS.

\subsection{Designing detailed lesson plans is a good approach} to learning IBL teaching

In our experience of running teachers' professional development projects, a remarkable finding is that training teachers to design a detailed lesson plan of a new teaching strategy step-by-step is very helpful for them in successfully implementing the new teaching strategy into their classroom teaching (Lin and Chin 2013). As for IBL, within the many strategies (e.g., 5E inquiry learning cycle of engagement, exploration, explanation, elaboration and evaluation, Bybee 1997); the predict-observe-explain POE learning model of White and Gunstone 1992; Siegel et al.'s 1998 inquiry teaching model), sophisticated teacher's and students' tasks are always required. Hence a detailed lesson plan is needed for a teacher to master the relevant teaching skills when conducting an IBL activity.

Directly providing a ready-designed IBL lesson plan could motivate a teacher to attempt to implement IBL teaching; however, this might be only helpful for the beginning and would not be a long-term solution. There are several obstacles hindering teachers from designing their own teaching activities, including: insufficient understanding of the students (Yoshida 2008), lack of explicit principles for designing IBL activities (Lin 2013a), and being unfamiliar with what kinds of materials could be adopted in the design of IBL tasks (Lin et al. 2012). A complete lesson plan should include a detailed teaching schedule and student worksheet. It is almost impossible for a teacher to finish a detailed lesson plan of a new teaching strategy in one step: in most cases, teachers start by designing a student worksheet, then extend it gradually to a more detailed lesson plan or even a teaching module. During this process, teachers need to continually carry out thought and teaching experiments and make improvements as they would in conducting action research. In this way, 
teachers develop sound professional growth during the process.

\subsection{Expert or learner? Change of attitudes makes the difference}

In Taiwan, perhaps because of the influence of Confucianism (Confucius is venerated as "the Most Sage and Greatest Teacher"), most of the teachers possess high selfesteem and consider themselves as having authority of knowledge over the students. This phenomenon is particularly true with mathematics teachers. Thus, being afraid that students might discover there are problems the teacher cannot solve causes very heavy pressure for the teacher. When promoting a new teaching strategy to mathematics teachers, a common response from the teachers is that their teaching is good enough and they do not need to make any change. During the running of LSMT, we clearly noticed this phenomenon, especially when the teacher educator came to lead the workshop as an "expert" who is to instruct the participant teachers how to teach. Teachers were concerned that their teaching practices were being criticized (Lin 2013a). Therefore, in the "Lighting Up" project, the teacher educators were encouraged to change their attitudes from an expert to a learner when leading an LSMT community. When we humbled ourselves first as being a learner (learning from the process of leading the professional development community), not playing the part of an expert or professor (looking down on these teachers from a higher hierarchical position), the teachers were less resistant and more willing to learn the new teaching strategy. This change of attitude helped to break down the invisible hierarchy between the teacher educator and these in-service teachers, and increase the mutual identification with the community, as well as the teachers' participation becoming more and more central to the functioning of the community, in the sense of the theory of Legitimate Peripheral Participation (LPP) (Lave and Wenger 1991)). In the same way, the teachers were also encouraged to swallow their pride before their students by confessing that they are not omniscient, and to use every chance to show their skills of IBL as an exemplar. The confession that they also need to learn helps to free teachers from pretending to be omniscient.

\section{Discussions and suggestions}

At the beginning of this commentary, we pointed out some reasons why IBL is not a common feature in the day-to-day mathematics teaching in Taiwan:
1. teachers did not experience IBL in mathematics when they were at school;

2. teachers do not have complete understanding of IBL/ IBME;

3. the allocated teaching hours are not enough;

4. the great influence of "teaching to the test";

5. being alone and lack of administrative support from school or government.

As our explanations show, LSMT addresses the impediments 1, 2 and 5: teachers get the chance to experience IBL and learn about IBL and its theoretical background; and obviously, by its very nature, teachers receive support from the government. However, the great influence of "teaching to the test" and, in connection with it, the number of allocated teaching hours, still remain as impediments.

"Teaching to the test" is a common phenomenon in classroom teaching all over the world. Especially the form of high stake examination dominates teachers' classroom teaching. Of course, if the patterns of assessment could be modified from stressing procedural fluency and knowledge recall to less restrictive modes that are supportive of students' inquiry, it would be definitely beneficial for implementing IBL practices in classrooms.

However, good mathematics learning means that students are able to develop the integrity of mathematical proficiency. According to Kilpatrick, Swafford and Findell's version, there are five strands of mathematical proficiency: conceptual understanding, procedural fluency, adaptive reasoning, strategic competence, and productive disposition (NRC 2001). If we consider that IBL is a better way of learning mathematics, we should have faith that the students can develop all the five strands of mathematical proficiency evenly. Therefore, when we can only passively accept the patterns of assessment (especially the high stake test), we should still be confident that IBL can help the students cope with these. This aspect also needs to be considered when designing professional development activities.

Being short of allocated teaching hours is not only a problem for mathematics, but also happens in most school subjects. Therefore, arguing for more teaching hours for teaching mathematics would not be feasible and we have to accept the reality. Although IBL activities do require more time compared with traditional expository teaching, it is a myth that IBL should be implemented in all classroom teaching. A counter to the argument of insufficient teaching hours might be suggested as follows. One of the powerful features of IBL is helping students construct their own understanding of mathematical concepts. When students better understand these, less time for practicing algorithms should be needed. Another myth is that all the contents in 
the textbook have to be "taught" in the classroom. However, teachers cannot warrant that what has been taught by them is actually learned by their students, nor that what their students have learned is all taught by them. Therefore, when students' motivation for learning is aroused by IBL activities, teachers can use homework as students' extended learning, and need not go through every detail of the contents in the textbook.

As aforementioned, designing detailed lesson plans can be a good approach to learning IBL teaching. In fact, whether a teacher is able to design a complete lesson plan for IBL could be a criterion to ascertain whether the teacher is ready to implement IBL in her/his teaching practice.

When reading this issue, we identified a gap between teachers' perceptions and the actualities of their teaching practices in Europe. This gap is worthy of further investigation. Therefore, if some data can be collected directly from these teachers' day-to-day classroom teaching, there will be concrete evidence for making more powerful conclusions.

To sum up, as in Europe, IBL is not widespread in dayto-day teaching in Taiwan. The impediments for the implementation of IBL relevant in Taiwan also seem to be applicable in Europe. Whilst, in Europe, the European Commission and some countries (see Krainer and Zehetmeier 2013) have launched projects and initiatives to make IBL more widespread in day-to-day teaching, in Taiwan the government has launched LSMT to change the situation. In Europe the implementation strategies differ from project to project (Maaß and Artigue 2013); in Taiwan we have had good experiences by providing schoolbased professional development focusing on lesson plans and changing attitudes.

\section{Final remarks}

Helping students foster their inquiry habits of mind and inquiry skills is one of the main purposes for promoting IBL in mathematics education. To achieve this needs time and a constantly supportive learning environment. Although it might be easier for the teachers to make a start by designing some extra off-class IBL activities, putting IBL into day-to-day classroom teaching practice should be the key. We look forward to seeing the popularization of IBL in Europe in the future, rather than only the participant teachers getting changed, as our former experience tells us that the "seed" teachers seldom blossom and bear fruit. Certainly the valuable experience of conducting large-scale projects such as those launched by the European Commission is worthy of consultation and reference by other countries.

\section{References}

Bybee, R. W. (1997). Achieving scientific literacy. Portsmouth, NH: Heinemann.

Chin, E.-T. (2008). A study of mathematics teacher professional development-inquiry-based instruction. Three-year research project report of National Science Council, Taiwan (in Chinese).

Chin, E.-T. (2011). A study on developing the design of conjecturing activity centered learning modules based on inquiry-oriented instruction and its evaluation. Three-year research project report of National Science Council, Taiwan (in Chinese).

Krainer, K., \& Zehetmeier, S. (2013). Inquiry-based learning for students, teachers, researchers, and representatives of educational administration and policy. Reflections on a nation-wide initiative fostering educational innovations. ZDM-The International Journal on Mathematics Education, 45(6) (this issue). doi:10.1007/s11858-013-0537-z.

Lave, J., \& Wenger, E. (1991). Situated learning: Legitimate peripheral participation. Cambridge, NJ: Cambridge University Press.

Lin, F.-L. (2013a). An innovative Lightening-Up program to overcome challenges of Taiwan mathematics education. Plenary panel at the 6th East Asia Regional Conference on Mathematics Education, March 17-22, 2013, Phuket.

Lin, F.-L. (2013b). Manual of "Lighting Up": Adjunct Project of "Light Spot for Mathematics Teaching". Ministry of Education, Taiwan (in Chinese).

Lin, F.-L., \& Chin, E.-T. (2013). A study on fostering mathematics teachers' professional growth through engaging in the design of mathematical task sequence. Research project report of National Science Council, Taiwan (in Chinese).

Lin, F.-L., \& Liu, M.-H. (2011). International civic and citizenship education study (ICCS 2009). Asian regional module. Paper presented at the 52nd IEA General Assembly, Dublin.

Lin, F.-L., Yang, K.-L., Lee, K.-H., Tabach, M., \& Stylianides, G. (2012). Principles of task design for conjecturing and proving. In G. Hanna \& M. de Villiers (Eds.), Proof and proving in mathematics education (pp. 305-325). New York: Springer.

Maaß, K., \& Artigue, M. (2013). Implementation of inquiry-based learning in day-to-day teaching-a synthesis. ZDM-The International Journal on Mathematics Education, 45(6) (this issue). doi:10.1007/s11858-013-0528-0.

Maaß, K., \& Doorman, M. (2013). A model for a widespread implementation of inquiry-based learning. ZDM-The International Journal on Mathematics Education, 45(6) (this issue). doi:10.1007/s11858-013-0505-7.

Mullis, I. V. S., Martin, M. O., \& Foy, P. (2008). TIMSS 2007 international mathematics report. Chestnut Hill, MA: TIMSS \& PIRLS International Study Center, Boston College.

Mullis, I. V. S., Martin, M. O., Foy, P., \& Arora, A. (2012). TIMSS 2012 international results in mathematics. Chestnut Hill, MA: TIMSS \& PIRLS International Study Center, Boston College.

National Council of Teachers of Mathematics. (1991). Professional standards for teaching mathematics. Washington, DC: National Academy Press.

National Research Council (2001). Adding it up: Helping children learn mathematics. J. Kilpatrick, J. Swafford, \& B. Findell (Eds.), Mathematics Learning Study Committee, Center for Education, Division of Behavior and Social Science and Education. Washington, DC: National Academy Press.

National Science Council (2006). The platform of High Scope program. http://highscope.ch.ntu.edu.tw/wordpress (Accessed 23 Sep 2013).

Organization for Economic and Co-operation Development. (2005). PISA 2003 technical report. Paris: Authors. 
Siegel, M., Borasi, R., \& Fonzi, J. (1998). Supporting students' mathematical inquiries through reading. Journal for Research in Mathematics Education, 29(4), 378-413.

White, R. T., \& Gunstone, R. F. (1992). Probing understanding. London: Falmer Press.

Yoshida, M. (2008) Exploring idea for a mathematics teacher educator's contribution to lesson study: towards improving teachers' mathematical content and pedagogical knowledge. In D. Tirosh \& T. Wood (Eds.), The international handbook of mathematics education. Tools and processes in mathematics teacher education (Vol. 2, pp. 85-108). New York: Springer. 